\title{
Sistema brasileiro de classificação dos meios de hospedagem (SBClass) na perspectiva dos hóspedes
}

Scheine Neis Alves da Cruz De Bastiani - Mestra em Administração. Faculdade de Tecnologia Senac Caçador - Brasil. scheine@sc.senac.br

Suzana Rodrigues Macedo - Mestra em Meteorologia. Faculdade de Tecnologia Senac Florianópolis - Brasil. suzana@prof.sc.senac.br

\section{RESUMO}

Este estudo tem como objetivo avaliar a legitimidade do Sistema Brasileiro de Classificação dos Meios de Hospedagem, na perspectiva dos hóspedes. Para tanto, empregamos uma pesquisa qualiquantitativa, dos tipos exploratório, descritivo, bibliográfico, documental e survey, sendo o instrumento de coleta de dados um questionário aplicado aos clientes da SBTur entre setembro e outubro de 2015. Para a análise desses dados utilizamos variados métodos estatísticos, desde frequência relativa, média simples, desvio padrão e distribuição Normal, até o teste de associação qui-quadrado e o coeficiente de correlação de Pearson. Considerando a comparação dos aspectos empíricos levantados com o aporte teórico, destaca-se que, para o sistema de classificação ser legítimo precisa ter como base a perspectiva do cliente, garantindo fidedignidade no processo de classificação, permitindo o uso do Sistema para seu verdadeiro fim, que visa subsidiar o consumidor com informações, mais próximas da realidade possível, conduzindo a uma escolha mais precisa do meio de hospedagem desejado.

Palavras-chave: SBClass. Meios de Hospedagem. Hóspedes. Clientes. Legitimidade.

\section{Brazilian system of classification of accomodation (SBClass) in the perspective of guests}

\begin{abstract}
This study aims to evaluate the legitimacy of the Brazilian System of Accommodation Rating from the point of view of the guests. For this purpose, we used a qualitative and quantitative research of the exploratory type, descriptive, bibliographical, documentary and survey, and the data collection instrument, a questionnaire applied to SBTur customers between September and October 2015. For the analysis of the data we used varied statistical methods, from relative frequency, simple mean, standard deviation and normal distribution, to the chi-square association test and Pearson's correlation coefficient. And, by comparing the empirical issues raised with the theoretical support, we emphasize that, in order to be legitimate, the classification system needs to be based on the customer's perspective, thus, ensuring reliability in the classification process, allowing the use of the system for its true purpose, which is to subsidize the consumer with information as close to reality as possible, leading to a more precise choice of the desired type of accommodation.
\end{abstract}

Keywords: SBClass. Accommodation. Guests. Customers. Legitimacy. 


\section{INTRODUÇÃO}

Os sistemas de classificação dos meios de hospedagem são aplicados em todo o mundo, logo, é importante mencionar que existem diferenças entre os vigentes em diversos países, principalmente no que se refere aos aspectos considerados para categorizar os meios de hospedagem (MINISTÉRIO DO TURISMO, 2010). Desse modo, neste estudo delimita-se como foco de pesquisa o próprio Sistema de Classificação aplicado no Brasil, ou seja, o "SBClass", sendo os meios de hospedagem compreendidos como empreendimentos que prestam "[...] serviços de alojamento temporário, ofertados em unidades de frequência individual e de uso exclusivo do hóspede, bem como outros serviços necessários [...], mediante adoção de instrumento contratual, tácito ou expresso, e cobrança de diária" (BRASIL, 2008).

Assim, o sistema de classificação deve representar todo o conjunto de elementos organizacionais que, de alguma forma, precisam interagir ou se relacionar, e para os quais um gestor e o governo voltam sua atenção porque têm o interesse de saber como se comportam em relação aos níveis de desempenho desejados, na perspectiva do hóspede. Para construir uma matriz mais próxima à realidade desses tipos de negócios, um sistema de classificação deve integrar as características dos diferentes meios de hospedagem, as necessidades e expectativas do público de cada empreendimento e, ainda abarcar a prestação do serviço e a qualificação dos colaboradores.

Um bom sistema de classificação deve enfim, valorizar as vantagens de cada tipo de meio de hospedagem ao hóspede e reconhecer a diversidade de cada tipo de negócio, visando um processo de avaliação mais inclusivo. Na expectativa de avaliar a legitimidade dos sistemas de classificação adotados, o presente estudo permitirá a associação dos dados a esse modelo teórico (SBClass), comparando os requisitos do sistema atual com a óptica dos hóspedes dos meios de hospedagem. O sistema de classificação oficial do Brasil supõe uma teoria de apoio para que se verifique se a realidade observada pelos hóspedes lhe corresponde. Ou seja, pretende-se levantar se os requisitos que os hóspedes observam e consideram estão contemplados no sistema de classificação oficial.

Porém, para que uma linguagem uníssona possa ser construída, é importante apresentar os termos comumente utilizados na literatura que se referem aos clientes dos meios de hospedagem. A partir de pesquisas bibliográficas foi possível perceber que os mesmos são identificados na maioria dos casos como "clientes" mesmo ou "consumidores", denominação equivalente a outros tipos de negócio. Entretanto, em outras publicações encontraram-se termos como: "usuário", "hóspede", "viajante", "visitante" e, até mesmo, "turista".

Para que esses aspectos pudessem ser evidenciados, realizou-se uma busca em quatro bases de dados (CAPES, EBSCO, SCIELLO e SPELL) utilizando os termos "meios de hospedagem", "clientes" e "hóspedes", combinados ou apenas indicando o termo "meios de hospedagem" de forma genérica, no intuito de conseguir maior amplitude nos resultados. Desse modo, foi possível verificar os diferentes termos empregados para mencionar os clientes dos meios de hospedagem. Durante o estudo optou-se pela a utilização de todos os termos, principalmente, valorizando a epistemologia de cada referência empregada.

\subsection{Objetivo geral}

Avaliar a legitimidade do Sistema Brasileiro de Classificação dos Meios de Hospedagem, na perspectiva dos hóspedes. 


\subsection{Objetivos específicos}

Para o alcance do objetivo geral, foram estabelecidos os seguintes objetivos específicos:

- Conhecer a estrutura do Sistema Brasileiro de Classificação dos meios de hospedagem (critérios e método de categorização);

- Levantar estudos que destaquem as necessidades, anseios, desejos e características dos hóspedes, que levam à satisfação;

- Aplicar questionário aos clientes do SBTur buscando a identificação do perfil e dos critérios avaliados nos meios de hospedagem;

- Comparar os aspectos empíricos levantados com o aporte teórico.

\section{DESENVOLVIMENTO}

A revisão teórica é aquela que dá corpo às pesquisas, fornece a base de sustentação para qualquer investigação científica. Por isso, nesse primeiro momento, destaca-se os principais termos, conceitos e modelos, bem como algumas referências que sustentem a problemática proposta. Inicialmente, é realizada uma breve contextualização sobre o Sistema de Classificação dos meios de hospedagem vigente no Brasil, para então, verificar e analisar, a partir de pesquisas realizadas, quais itens são considerados pelos clientes/hóspedes para sua estadia e, se estes aspectos são contemplados pelo Sistema.

\subsection{Sistemas de classificação}

Os sistemas de classificação dos meios de hospedagem são aplicados em todo o mundo, existindo diferenças entre os vigentes nos mais variados países (MINISTÉRIO DO TURISMO, 2010). Desse modo, para este estudo, delimitou-se como foco o Sistema Brasileiro de Classificação dos Meios de Hospedagem (SBClass). Porém, para se chegar à classificação que se tem hoje, inúmeros ajustes precisaram ser executados.

Por isso, em 2008 o Ministério do Turismo juntamente com Inmetro, a Sociedade Brasileira de Metrologia e a Sociedade Civil, iniciou os estudos para a efetiva implantação do novo Sistema Brasileiro de Classificação de Meios de Hospedagem (SBClass) (MINISTÉRIO DO TURISMO, 2010).

Assim, em 2010 o novo Sistema foi apresentado, sendo sancionado em 2011, pela Portaria no 100, de 16 de Junho de 2011, estando vigente hoje e baseado em premissas modernas no intuito de inserir, cada vez mais, um padrão internacional na hotelaria brasileira (MENEZES; SILVA, 2013; MINISTÉRIO DO TURISMO, 2010).

Dessa forma, no atual Sistema de Classificação Brasileiro há uma divisão de todas as suas matrizes de análise em três categorias: infraestrutura, serviços e sustentabilidade, ou seja, são três eixos principais para apreciação no momento da concessão de uma categoria. Portanto, o SBClass foi elaborado tendo como base requisitos ditos como mandatórios (obrigatórios) e eletivos (opcionais), fazendo uso da "consagrada simbologia de estrelas para diferenciar as categorias, em todas as tipologias de meios de hospedagem" (MINISTÉRIO DO TURISMO, 2010, p. 06).

A partir disso, Menezes e Silva (2013) destacam a importância de o Sistema não ignorar a diversidade dos meios de hospedagem existentes, e ainda de não permanecer no erro de desconsiderar as variações significativas do público na área do turismo, ou seja, ratificando a 
relevância de ver a classificação com o olhar dos seus usuários/clientes/hóspedes.

É importante esclarecer que, tal como a realidade de outros países, no Brasil a adesão é voluntária ao Sistema de Classificação, ou seja, os meios de hospedagem têm liberdade de se candidatar ou não. Contudo, se essa escolha for realizada, os interessados tem a possibilidade de galgar uma das categorias que devem atender a todos os requisitos mandatórios (100\%), e ao menos $30 \%$ dos eletivos, precisando executar um processo específico com preenchimento de formulários, apresentação de documentos e visita in loco de um representante do Inmetro (MINISTÉRIO DO TURISMO, 2010).

Nesse sentido, um sistema de classificação realmente abrangente "valoriza as vantagens de cada tipo de meio de hospedagem e reconhece a necessidade da diversidade na hotelaria" (MENEZES; SILVA, 2013, p. 68). Principalmente, pelo fato dos meios de hospedagem estarem em constante busca por "[...] novas fórmulas quanto a outros serviços [...], com o objetivo de ser mais competitivo, conseguir maiores receitas, maiores lucros e rentabilidade, e um posicionamento mais sólido no mercado" (MONTEJANO, 2001, p. 151).

2.1.1 Aspectos considerados importantes pelo hóspede nos diferentes meios de hospedagem versus Sistema de Classificação Brasileiro

Após conhecer a estrutura do SBClass, destaca-se que os meios de hospedagem e sua qualidade, são medidos através de estrelas. Assim considerado, o olhar volta-se sobre a legitimidade dessa classificação ao apreender se esta é uma boa referência para analisar a qualidade dos serviços e hospitalidade desses locais, e se os requisitos de qualidade levados em conta são os mesmos que os hóspedes consideram em sua avaliação.

Desse modo, é possível buscar os aspectos considerados importantes pelo cliente/hóspede nos diferentes meios de hospedagem, para posteriormente considerar a comparação entre essas duas perspectivas, ou seja, clientes e sistemas de classificação.

Contudo, antes de iniciar, é importante destacar que a classificação surgiu tendo como objetivo orientar os clientes a respeito dos aspectos físicos e operacionais que poderiam ser encontrados nos diversos tipos e categorias de meios de hospedagem. Sendo considerado, portanto, o modo mais adequado para o consumidor fazer a escolha do meio de hospedagem que deseja utilizar (MENEZES; SILVA, 2013; MINISTÉRIO DO TURISMO, 2010).

Por isso, é oportuno o levantamento dos aspectos que os clientes/hóspedes levam em consideração em suas escolhas, verificando se estão ou não contemplados nas categorias existentes e se esta classificação é um efetivo instrumento auxiliador nesse processo. Assim, notase, que dentro do setor de turismo e, mais especificamente, dos meios de hospedagem, "o cliente é a principal estrela, é ele quem deve orientar todos os passos a ser tomados e direcionar as ações de todos os profissionais envolvidos" (TUCH; SPOLON, 2001, p. 353).

A partir dessa breve contextualização, é possível apresentar os enfoques teóricos pertinentes. Para isso, partiu-se da compreensão que para o planejamento de viagens, uma parcela significativa de pessoas tem como prioridade a escolha das acomodações, ou seja, a seleção do meio de hospedagem mais adequado, gastando a maior parte do tempo nesse processo, possuindo expectativas e/ou preferências individuais, conforme seu destino, razão e forma de viagem, além de experiências anteriores com meios de hospedagens (LI et al., 2015). Desse modo, de acordo com a declaração de Herculano de A. Iglesias, presidente da Associação da Indústria de Hotéis (ABIH), em 1999, destacada na obra de Martineli (2001, p. 147), “[...] 'a hotelaria representa a espinha dorsal da indústria do turismo', deixando, portanto, de ser apenas ponto de apoio para ser um grande foco de investimento e renda". Observa-se, então, a notória importância dos meios de 
hospedagem para o equilíbrio do setor de turismo como um todo, tanto do ponto de vista de seus gestores como de seus clientes.

Entretanto, é difícil para os gestores de meios de hospedagem obter a compreensão plena dos requisitos adotados pelos clientes no momento de sua tomada de decisão, abrangendo uma ampla variedade de critérios de seleção (LI et al., 2015). Desses critérios, segundo os levantamentos bibliográficos de Li et al. (2015), os que possuem mais destaque estão relacionados com localização, preço, instalações e limpeza; ficando em segundo plano características como o tamanho, tipo de edificação, qualidade de serviço e um ambiente tranquilo (LOCKYER, 2005; ALBALADEJO-PINA; DIAZ-DELFA, 2009; MERLO; DE SOUZA JOÃO, 2001 apud LI et al., 2015).

Percebe-se então que "a preferência do viajante é imprevisível", o que acaba por influenciar, segundo Li et al. (2015, p. 311) "o desempenho de empresas hoteleiras, criando assim a necessidade de identificar e resolver as demandas de seus clientes", mesmo que essas ainda não estejam claramente determinadas pelos próprios clientes. Isso ratifica a questão em relação aos critérios do Sistema de Classificação, uma vez que se não estão claras ou ainda imprevisíveis as demandas dos clientes, como afirmar que seus critérios de escolha estão em sintonia com àqueles da classificação? No turismo, pode-se dizer que a satisfação é representada pela obtenção de algo, mas indo "além disso, pois alcança a esfera social e psicológica do indivíduo, sendo que a satisfação do consumidor não depende única e exclusivamente da qualidade ou do preço do produto ofertado" (CANDIOTO, 2012, p. 38).

De acordo com Li et al. (2015, p. 313), "alguns aspectos podem ser importantes para todos os viajantes, ao passo que outros podem ser significativos apenas a um subgrupo específico", ou ainda, que são levados em consideração para classificá-los como cinco estrelas, mas que para os viajantes isso não os leva a se enquadrar nessa classificação de excelência.

Por isso, Candioto (2012, p. 38) faz uma reflexão, destacando que o turista não compra preço, hotel cinco, quatro ou três estrelas, nem muito menos transporte, mas compra a oportunidade de viver "uma experiência, que pode ser diferente para cada pessoa e depende muito de suas características e valores individuais".

No contexto de serviços, no qual se enquadra os meios de hospedagem, a qualidade está pautada pela satisfação das expectativas e necessidades dos clientes, e não apenas as características e padrões pré-estabelecidos (PARASURAMAN; ZEITHAML; BERRY, 1985; FERNÁNDEZ; BEDIA, 2004). Desse modo, "não é possível reconhecer a qualidade apenas em serviços e artigos de luxo, mas sim em todos aqueles que respondem ao que o consumidor procura" (FERNÁNDEZ; BEDIA, 2004, p. 771).

Satisfação é o que toda organização busca proporcionar a sua clientela e no segmento de meios de hospedagem, não seria diferente mesmo precisando adaptar-se constantemente às mudanças da sociedade. "Os estudos da satisfação tem se tornado fundamentais para aumentar o relacionamento entre hóspedes e os hotéis" (LADEIRA; SANTINI; COSTA, 2013, p. 119).

Por isso, é importante perceber o que o hóspede leva em consideração para sentir-se satisfeito caracterizando o serviço como de qualidade, já que analisando várias pesquisas foi possível verificar que o hóspede não destaca que luxo é sinônimo de qualidade, até porque os hotéis com uma estrela são os que atendem melhor as perspectivas dos clientes (SANTOS, 2013; LIMBERGER; BOARIA; ANJOS, 2014).

De acordo com a pesquisa realizada por João, Merlo e Morgado (2010), a qual teve como foco meios de hospedagem classificados como "hotéis econômicos", ou seja, duas estrelas, podese perceber que essa categorização não é levada em consideração no momento de escolha do meio de hospedagem pelos clientes, mas o menor preço de diárias e a prestação de serviços ágil e confiável. 
Santos (2013) destaca que o requisito principal levado em consideração pelo cliente é a hospitalidade. Esta envolve "[...] a arte de receber, hospedar, alimentar, entreter e despedir-se do visitante" (CASTELLI, 2010 apud ANGELI, 2010, p. 144), A hospitalidade funciona como uma diretriz do comportamento das organizações do ramo dos meios de hospedagem. Por isso, é importante destacar que "[...] dificilmente um hotel atenderá às necessidades, aos desejos e às expectativas dos viajantes se não possuir uma estrutura física e um atendimento perfeitamente adequados" (CASTELLI, 2010 apud ANGELI, 2010, p. 145).

Além disso, nota-se que o hóspede prefere sentir-se bem quando se instala em um local, ao invés de estar instalado em um local de luxo. Instalações luxuosas e grandes são um indicativo de qualidade para muitos, mas o mais comum é o hóspede querer conforto quando está longe de casa (SANTOS, 2013; LIMBERGER; BOARIA; ANJOS, 2014).

A imagem vista pelos hóspedes dos meios de hospedagem é uma característica que pode afetar positivamente ou negativamente a rede hoteleira, principalmente, por suas necessidades e expectativas serem ditas como imprevisíveis (KARASSAWA, 2003; LI et al., 2015), como já mencionado. Com isso, a mídia pode ser uma ferramenta influenciadora da imagem a ser construída, precisando ser bem explorada, já que "o setor hoteleiro se apresenta como um dos [...] mais expostos às mudanças causadas pelas mídias sociais" (LIMBERGER; BOARIA; ANJOS, 2014, p. 45).

A partir dessa revisão teórica foi possível perceber que existem diferenças significativas nos critérios utilizados pelos hóspedes, no que tange a classificação de um meio de hospedagem como de qualidade e que satisfaça suas necessidades e desejos. Conforme Martineli (2001, p. 150), "quando se está hospedado em um hotel, as expectativas pessoais são bem maiores, pois se espera sempre muito mais do que o solicitado e do que está sendo pago".

Nesse sentido pode-se considerar aquilo que Vaz (2002) aponta sobre as fontes motivadoras que levam os indivíduos a viajar e, consequentemente, na maioria das vezes, utilizar os meios de hospedagem. Essas fontes contemplam desde motivações pessoais, a busca de turismo ou tratamentos de saúde; passando por aspectos familiares, envolvendo compromissos de família e visita a parentes distantes; também menciona uma fonte social, que é semelhante à familiar, porém abrange compromissos comunitários, esportivos ou associativos em geral; e até organizacionais, ou seja, a obrigatoriedade da viagem em virtude de razões corporativas.

Além dessas motivações, Vaz (2002) ainda descreve o que as pessoas buscam a partir de seus deslocamentos e permanência em meios de hospedagem, estando complemente interligados. Pode-se destacar: mudança de ambiente, repouso, recreação, tratamento, aquisição/troca de conhecimentos, projeção social, funcionalidade, praticidade e economia (VAZ, 2002).

Dessa maneira, é possível apontar que para a estruturação de uma classificação dos meios de hospedagem na perspectiva dos hóspedes, é importante verificar as características dos mesmos, suas motivações e o que realmente buscam, ou seja, construir um perfil, pois dependendo disso tudo, os aspectos considerados relevantes para o cliente serão alterados. Isso significa que a cada tipo de cliente, deverão ser estabelecidos critérios primordiais na hora de conferir uma categoria aos meios de hospedagem.

\subsection{Procedimentos metodológicos}

A metodologia estabelece a forma de organização de uma pesquisa científica, destacando como a mesma será operacionalizada, partindo da caracterização da pesquisa, tendo como base os instrumentos aplicados, bem como os indivíduos e o ambiente que serão investigados. Para, por 
fim, executar as devidas análises e interpretações, através de métodos objetivos, comparativos ou teóricos.

\subsubsection{Caracterização da pesquisa}

A presente pesquisa caracteriza-se como "qualiquantitativa", fazendo uso de relatos, descrições e características do Sistema Brasileiro de Classificação de Meios de Hospedagem (SBClass) e aplicando métodos estatísticos, para tabulação e análise dos dados dos questionários aplicados aos hóspedes/clientes dos meios de hospedagem.

Este estudo é exploratório, uma vez que investigou um campo específico, ou seja, o Sistema de Classificação dos meios de hospedagem na perspectiva dos clientes/hóspedes. Após a exploração, é preciso descrever "os achados de pesquisa", investindo-se numa análise descritiva abrangendo a aplicação de uma "técnica padronizada de coleta de dados, realizada principalmente através de questionários e da observação sistemática", permitindo que os fatos sejam "observados, registrados, analisados, classificados e interpretados" (ANDRADE, 2006, p. 124).

Diante disso, observa-se a pesquisa pode ainda ser classificada como de levantamento ou survey, pois por meio de questionários, os quais serão apresentados na sequência, foi feito um levantamento de informações diretamente com os clientes/hóspedes, para "[...] em seguida, mediante análise quantitativa, obterem-se as conclusões correspondentes aos dados coletados" (GIL, 2002, p. 50), ou seja, a legitimidade do Sistema de Classificação na perspectiva do cliente.

Nota-se a importância do aporte bibliográfico, subsidiando as análises, bem como norteando a verificação da classificação na perspectiva dos clientes. Outros fatores estão envolvidos, abrangendo as características e as necessidades individuais desses consumidores. Além de bibliografias, também documentos em geral (relatórios, manuais, formulários, esquemas) são fontes importantes para o embasamento de pesquisas científicas. Portanto, destaca-se a Cartilha de Orientação Básica do Sistema Brasileiro de Classificação de Meios de Hospedagem (MINISTÉRIO DO TURISMO, 2010), juntamente com a legislação que o sancionou (Portaria $\mathrm{n}^{\circ}$ 100/2011, do Ministério do Turismo) como documentos adicionais, os quais apontam todos os aspectos relevantes para o entendimento do SBClass e, assim a concretização do estudo sobre sua efetividade perante os clientes.

\subsubsection{Procedimentos de coleta de dados}

Como já mencionado, o questionário foi o instrumento escolhido para o levantamento das informações. Buscou-se conhecer o comportamento, ou seja, os hóspedes/clientes e sua perspectiva sobre o SBClass. Desse modo, foram elaborados cinco questionários distintos, focando diferentes tipos de meios de hospedagem, sendo eles: hotel, hotel fazenda, flat/apart-hotel, pousada e resort. Esse instrumento é composto por dois blocos de questões, o primeiro, baseado em três perguntas abertas e três fechadas, busca conhecer o perfil do hóspede (estado em que reside, idade, sexo, motivo em geral de suas viagens e tipo de meio de hospedagem que costuma escolher).

O segundo bloco é constituído por duas perguntas fechadas, cuja primeira busca identificar se o hóspede/cliente levou em conta o número de estrelas para escolher o meio de hospedagem. Já a segunda pergunta considera os critérios descritos pelo SBClass para classificar os meios de hospedagem, optando principalmente por aqueles apontados pela categoria cinco estrelas. O objetivo era que o hóspede analisasse o nível de importância que cada critério possui em sua escolha por um meio de hospedagem, com isso, tem-se a oportunidade de verificar se o 
que está descrito no sistema de classificação é condizente com as expectativas dos hóspedes.

É importante mencionar que o rol de critérios a ser avaliado pelo respondente está condicionado a sua opção para a última questão do primeiro bloco de perguntas (Em geral, você se hospeda em que tipo de meio de hospedagem?). Para melhor compreender o processo, destaca-se que o referido questionário foi estruturado dentro da ferramenta Google Docs. Quando escolhida a opção do meio de hospedagem usual, o respondente é direcionado para uma nova página que apresentará os critérios correspondentes àquele meio de hospedagem, os quais devem ser avaliados.

Logo, a escala tipo Likert permite a efetiva classificação da importância dos atributos investigados, já que "trata-se de uma escala de 5 ou 7 pontos [...] destinada a avaliar o grau de concordância das afirmações" ajudando "a aumentar a fidedignidade do instrumento" (THOMAS; NELSON; SILVERMAN, 2012, p. 228). Nessa pesquisa, o processo de avaliação dos critérios seguiu cinco pontos: i) sem importância; ii) pouco importante; iii) indiferente; iv) importante e v) muito importante.

Para realização da pesquisa, o universo compreendeu 5.670 clientes ativos do SBTur, o qual "possui uma rede com 20 agências de viagens franqueadas, espalhadas pelas principais cidades do sul e sudeste do Brasil", além de contar com alta tecnologia para execução de pesquisas e organização de viagens (SBTUR, 2015). Percebe-se, então, que não foram delimitados os tipos de meios de hospedagem a serem pesquisados, nem suas categorias, mas os clientes que em algum momento fizeram uso desses estabelecimentos. Logo, não se avaliou o meio de hospedagem em que o mesmo se encontra ou fez uso, mas sim o que ele considera importante no tipo de meio de hospedagem de sua preferência.

Para tanto, os questionários foram encaminhados pelo SBTur aos seus clientes via e-mail, com um texto explicativo, determinando um período de trinta dias para preenchimento (setembro a outubro de 2015). Após o período estipulado foram obtidas 86 respostas, sendo as mesmas utilizadas como base para as devidas análises do presente estudo.

\subsubsection{Procedimentos para análise dos dados}

Para a análise das 86 respostas obtidas no universo pesquisado, utilizou-se a frequência relativa dos primeiros dados, permitindo a elaboração de um perfil para os clientes, conforme anteriormente mencionado. Sendo esse determinado, pôde-se iniciar a análise exploratória dos critérios de valorização dos meios de hospedagem, realizada através de diferentes tipos de cálculos estatísticos.

Entre esses cálculos destacam-se: frequência relativa, média simples, desvio padrão e distribuição Normal. Esses métodos tem como objetivo avaliar a concentração dos dados em relação à opinião de maior estabilidade no conjunto.

Além da análise individual dos critérios, realizou-se a verificação de uma possível associação entre dois ou mais critérios, sendo que, duas variáveis, ou neste estudo chamados "critérios de valorização", estarão associadas se o conhecimento de uma alterar a probabilidade de algum resultado da outra (MORETTIN; BUSSAB, 2013). Para isso, utilizou-se o teste de associação qui-quadrado $\left(x^{2}\right)$, o mais antigo e um dos mais usados em pesquisa social (BARBETTA, 2010), sendo que as variáveis de interesse na investigação foram dispostas em tabelas de contingência para que duas hipóteses fossem testadas.

Para o cálculo do coeficiente qui-quadrado utilizamos a expressão: 


$$
\chi 2=\sum_{i}^{n} \frac{(O-E)^{2}}{E} \quad \begin{aligned}
& \text { Onde: } \\
& E=\text { frequência esperada } \\
& O=\text { frequência observada }
\end{aligned}
$$

Sendo que para a obtenção das frequências esperadas (E) a partir dos dados da tabela de contingência, utilizamos a expressão:

$$
E=\frac{(\text { total na linha }) \cdot(\text { total na coluna })}{(\text { total na amostra })}
$$

Complementando, avaliou-se o grau de correlação entre alguns pares de critérios de valorização dos meios de hospedagens. Essa análise permite avaliar quantitativamente a associação de comportamento entre duas diferentes variáveis (critérios). Para se medir o grau de correlação entre duas variáveis utilizou-se o coeficiente de correlação de Pearson $(r)$, sendo o mesmo obtido a partir da seguinte expressão:

Onde:

$x_{i}=$ observações de uma das variáveis investigadas

$$
r=\frac{\sum_{i=1}^{n}\left(x_{i}-\bar{x}\right)\left(y_{i}-\bar{y}\right)}{(n-1) s_{x} s_{y}}
$$

$\mathrm{y}_{\mathrm{i}}=$ observações de uma das variáveis investigadas

$\overline{\mathrm{x}}=$ média observada na variável $\mathrm{x}$

$\bar{y}=$ média observada na variável y

$(n-1)=$ graus de liberdade

$\mathrm{s}_{\mathrm{x}}=$ desvio padrão no conjunto de variáveis $\mathrm{x}$

$\mathrm{s}_{\mathrm{y}}=$ desvio padrão no conjunto de variáveis $\mathrm{y}$

\subsection{Apresentação, análise dos dados e resultados}

Nas seções seguintes são apresentados os resultados e análises.

\subsubsection{Apresentação do perfil dos respondentes}

Os resultados obtidos, por meio da presente pesquisa, demonstram um perfil predominante de consumidor de serviços de hospedagem: maduro ( $78 \%$ acima dos 40 anos), feminino (62\%), por motivação principal de passeio (85\%) e proveniente principalmente do Estado vizinho Rio Grande do Sul e do interior de Santa Catarina, destacando a importância do turismo interno do Estado. O gráfico 1 mostra que uma porcentagem significativa dos respondentes prefere os meios de hospedagem classificados como "hotéis". 
Gráfico 1 - Tipo de meios de hospedagens utilizado

\title{
Tipo de meios de hospedagens utilizado
}

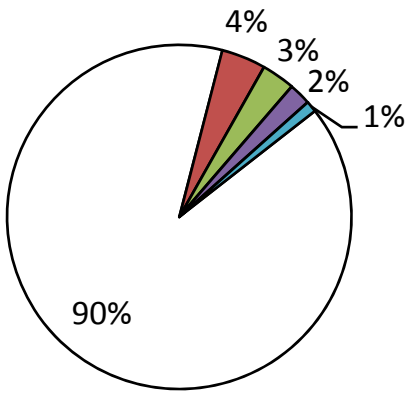

\author{
$\square$ Hotel \\ $\square$ Pousada \\ $\square$ Resort \\ $\square$ Flat/Apart Hotel \\ $\square$ H. Fazenda
}

Fonte: Elaborado pelos autores (2016)

Com esse perfil definido pode-se iniciar as análises qualitativas e quantitativas dos critérios de valorização dos meios de hospedagem, considerando ainda o SBClass para aprofundar e abrir caminho para discussões e inferências sobre a realidade pesquisada e o contexto geral do segmento dos meios de hospedagem.

\subsubsection{Análise dos critérios de valorização dos meios de hospedagens}

A identificação dos principais pontos considerados para valorização dos meios de hospedagens utilizados pelos hóspedes foi desenvolvida através de diferentes critérios, os quais foram avaliados por 86 hóspedes respondentes, que classificaram cada critério de valorização segundo a escala demonstrada no Quadro 1.

\begin{tabular}{|c|c|}
\hline \multicolumn{2}{|c|}{ Quadro1 - Escala } \\
\hline Conceito & Descrição \\
\hline 1 & sem importância \\
\hline 2 & pouco importante \\
\hline 3 & indiferente \\
\hline 4 & importante \\
\hline 5 & muito importante \\
\hline
\end{tabular}

A análise exploratória dos critérios de valorização dos meios de hospedagem considerados neste trabalho foi realizada em diferentes tipos de cálculos estatísticos.

Conforme a Tabela 1, os critérios de maior relevância (preferência acima de 40\%) para a valorização dos meios de hospedagens em Santa Catarina foram àqueles relacionados ao conforto do hóspede, tais como: disponibilização de colchões com tamanho grande, minirefrigerador no quarto, TV por assinatura, estacionamento próprio, a percepção de treinamento dos funcionários e facilidades de pagamento como cartões de débito e crédito. Destaca-se ainda a valorização da prática de reciclagem de materiais, como indicativo de que a preocupação com o meio ambiente é também um fator de decisão importante para o hóspede. 
Tabela 1 - Frequência relativa aos critérios de valorização dos meios de hospedagem em Santa Catarina

\begin{tabular}{llllll} 
& \multicolumn{5}{c}{ Escala de valorização (\%) } \\
\cline { 2 - 6 } Critério de valorização & $\mathbf{1}$ & $\mathbf{2}$ & $\mathbf{3}$ & $\mathbf{4}$ & $\mathbf{5}$ \\
\hline Colchões com padrões grandes & 1,2 & 1,2 & 8,1 & 33,7 & 55,8 \\
Berço disponível & 22,1 & 3,5 & 25,6 & 29,1 & 19,8 \\
Facilidades para bebês (como cadeiras) & 19,8 & 2,3 & 22,1 & 36 & 19,8 \\
TV por assinatura & 5 & 0 & 8 & 33 & 55 \\
Sala de ginástica e/ou musculação & 7 & 12 & 34 & 36 & 12 \\
Salão de eventos & 17 & 12 & 50 & 17 & 3 \\
Minirefrigerador & 1 & 1 & 2 & 42 & 46 \\
Bar & 6 & 1 & 19 & 47 & 28 \\
Estacionamento & 2 & 2 & 5 & 26 & 65 \\
Serviço de manobrista & 9 & 12 & 35 & 28 & 16 \\
Loja de conveniência & 14 & 14 & 48 & 20 & 5 \\
Locação de automóvel & 14 & 12 & 49 & 20 & 6 \\
Transporte especial & 13 & 14 & 42 & 21 & 10 \\
Salão de beleza & 20 & 9 & 49 & 16 & 6 \\
Farmácia & 13 & 8 & 37 & 33 & 9 \\
Jornais à disposição & 10 & 1 & 33 & 37 & 19 \\
Reciclagem de materiais & 7 & 3 & 13 & 35 & 42 \\
Serviço de pesquisa de opinião & 2 & 1 & 9 & 29 & 35 \\
Treinamento de funcionários & 6 & 3 & 10 & 38 & 42 \\
Pagamento com cartão débito/crédito & 1 & 0 & 1 & 10 & 87 \\
\hline
\end{tabular}

Fonte: Elaborado pelos autores (2016)

É oportuno mencionar também alguns critérios considerados indiferentes pelo público respondente, ou seja, que tiveram frequência relativa acima de $40 \%$ no item 3 (indiferente) da escala, entre eles destacam-se: salão de eventos, loja de conveniência, locação de automóvel, transporte especial e salão de beleza (Tabela1). No SBClass esses aspectos são mandatórios, ou seja, obrigatórios para que um hotel seja considerado 5 estrelas.

A amostra sugere que esses investimentos sejam direcionados aos critérios ditos como importantes e muitos importantes para os clientes/hóspedes, gerando um resultado mais expressivo. Por isso, outros critérios de valorização, associados à estrutura do meio de hospedagem, foram analisados de forma a avaliar a sua concentração em relação à opinião de maior estabilidade no conjunto, conforme gráficos 2 a 5 . 
Gráfico 2 - Histograma de frequências da valorização do meio de hospedagem por oferecer serviço de mensagem $24 \mathrm{~h}$

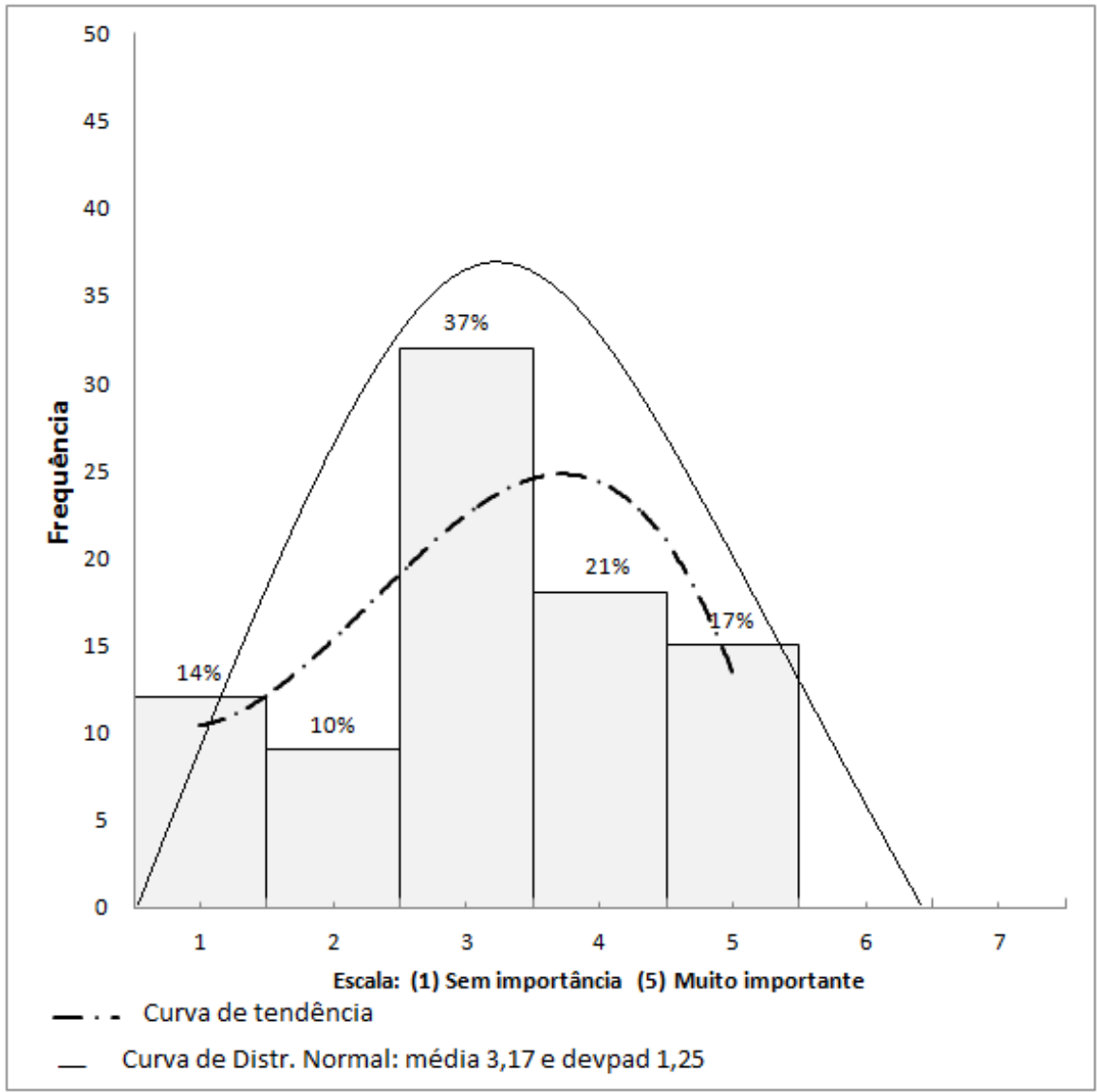

Fonte: Elaborado pelos autores (2016)

Analisando o gráfico 2, os retângulos justapostos indicam a frequência relativa de aparecimento das opiniões dadas na escala de 1 a 5 . A curva contínua representa a distribuição Normal dos dados em torno da média 3,17. Considerando o desvio padrão de 1,25, podemos afirmar que aproximadamente $70 \%$ dos dados estão próximos à média, com valores entre 1,92 e 4,42. Comparando esses valores com a escala de 1 a 5, os hóspedes dão pouca importância ao oferecimento de serviços de mensagens 24 horas, podendo considerar este serviço indiferente na obtenção de resultados positivos juntos aos hóspedes. Tomando, novamente, por base o SBClass, a inferência anterior se repete, o oferecimento de serviços de mensagens 24 horas é mandatário, contudo, indiferente para o cliente. 
Gráfico 3 - Histograma de frequências da valorização do meio de hospedagem através do critério serviço de recepção aberto $24 \mathrm{~h}$

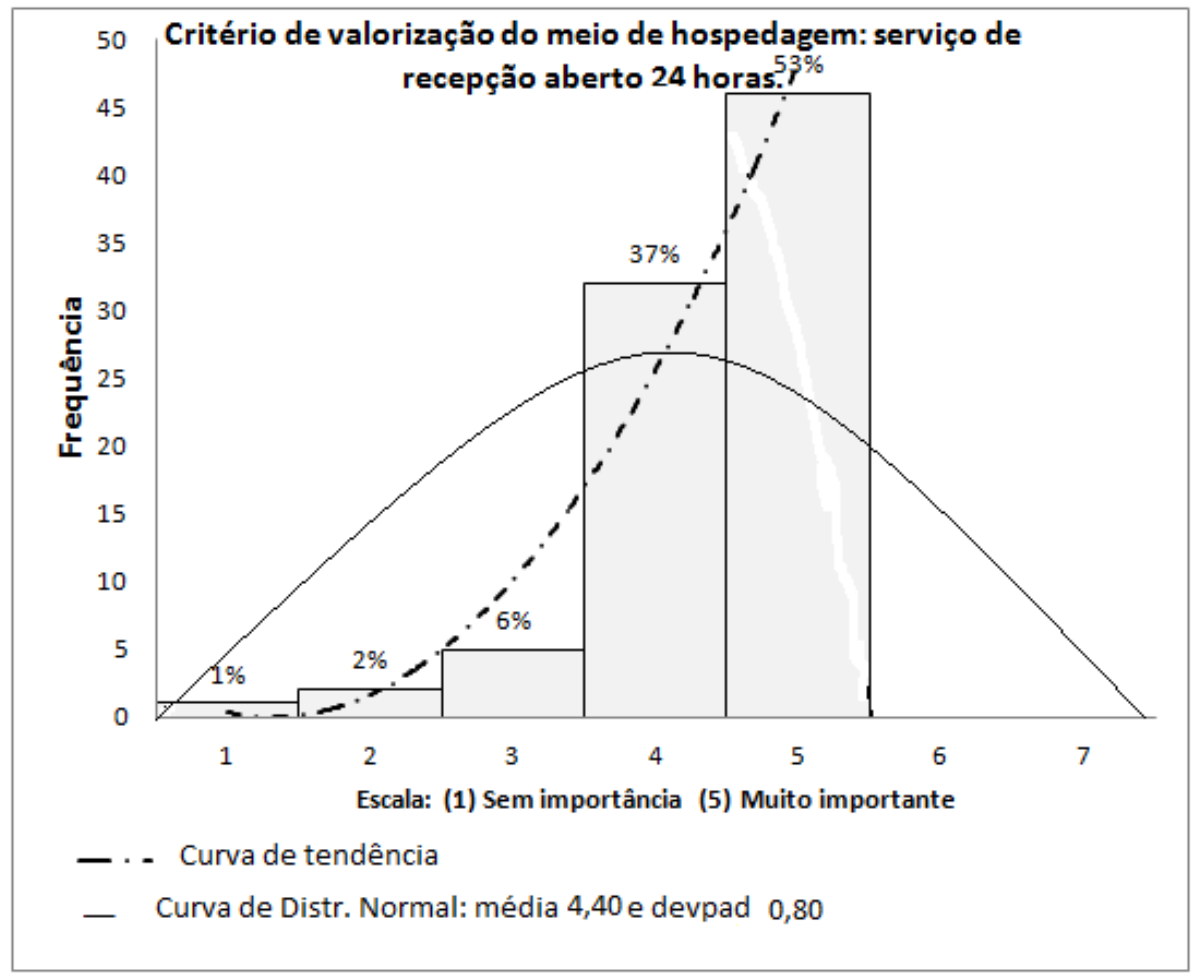

Fonte: Elaborado pelos autores (2016)

Em relação ao gráfico 3, a curva contínua representa a distribuição Normal dos dados em torno da média 4,40. Considerando o desvio padrão de 0,80, podemos afirmar que aproximadamente $70 \%$ dos dados estão próximos à média, com valores entre 3,6 e 5,20, ou seja, comparando estes valores com a escala de 1 a 5 , podemos afirmar que os hóspedes dão importância relativamente alta ao oferecimento de serviços de recepção que funcione durante 24 horas. O histograma com as frequências relativas mostra que mais $80 \%$ dos hóspedes consideram importante ou muito importante o oferecimento deste serviço por parte dos meios de hospedagens, sendo que a análise modal $(\mathrm{Mo}=5)$ nos garante que a opinião predominante é a de que este serviço é muito importante. Nesse caso, o oferecimento de serviços de recepção que funcione durante 24 horas, também é mandatário, mas é considerado muito importante, ratificando a relevância de sua obrigatoriedade em um hotel cinco estrelas. 
Gráfico 4 - Histograma de frequências da valorização do meio de hospedagem segundo o critério serviço de cofre

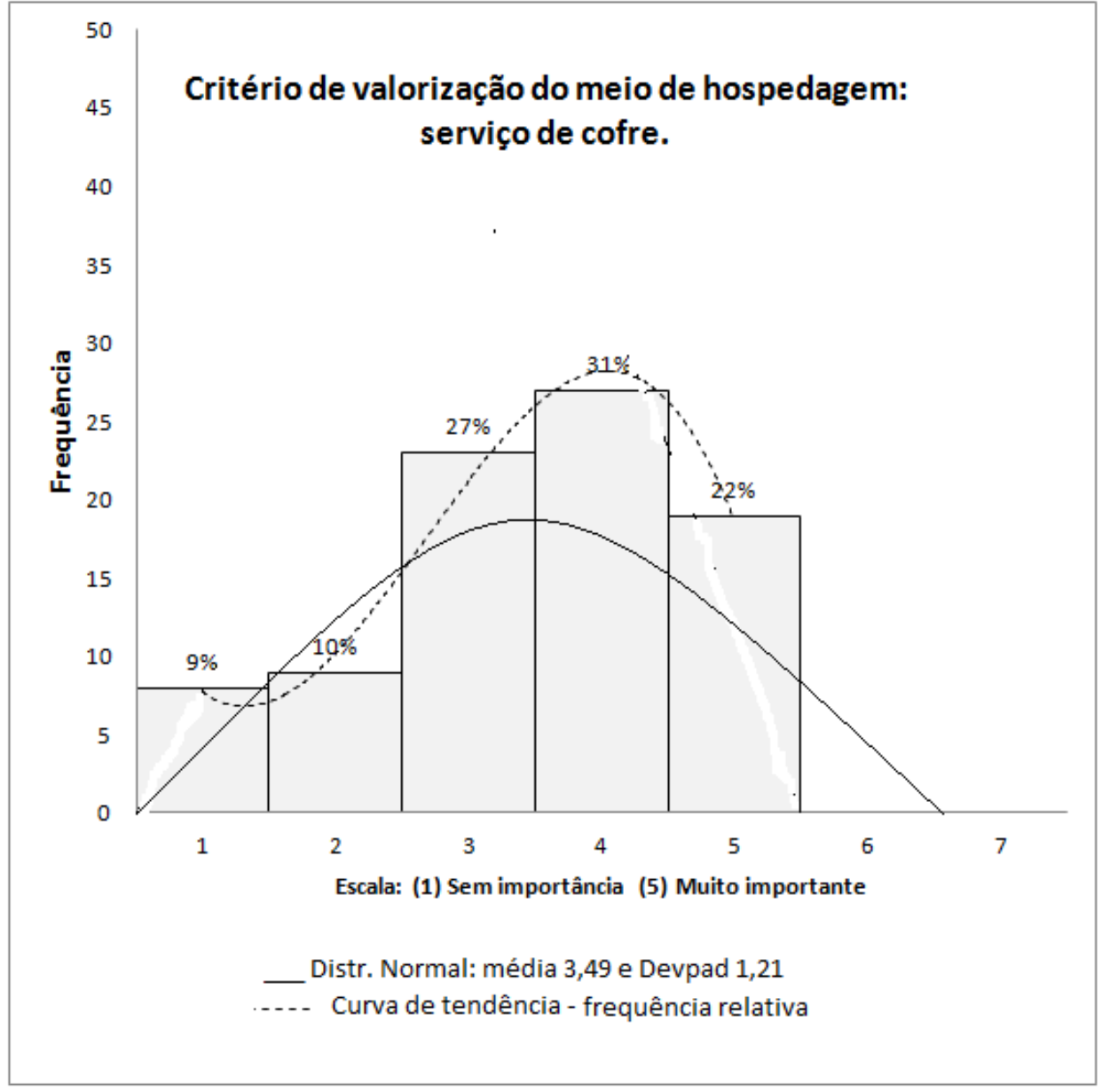

Fonte: Elaborado pelos autores (2016)

O gráfico 4 apresenta as opiniões dos hóspedes quanto à valorização do meio de hospedagem segundo o critério serviço de cofre. Em relação a esse quesito, a valorização dos meios de hospedagens é dispersa, com classificação média de 3,49 e desvio padrão de 1,21. A curva Normal nos garante uma porcentagem de $70 \%$ dos hóspedes se dividem nas opiniões que variam de 2 a 5 . Ou seja, com a medida de um desvio padrão as opiniões encontram-se bastante diferentes em torno da opinião média. Através da análise da curva Normal, não é possível agregar valor ao quesito possuir cofre, portanto.

No entanto, com o histograma das frequências relativas encontra-se concentrado à direita da média da curva Normal, podemos afirmar que a tendência dos hóspedes é em observar o fato do meio de hospedagem possuir cofre como um critério de valorização do meio de hospedagem. O cofre também é um serviço mandatário, perante o SBClass, e a sua relevância para o cliente confirma essa condição. 
Gráfico 5 - Histograma de frequências da valorização do meio de hospedagem segundo o critério área útil da unidade habitacional

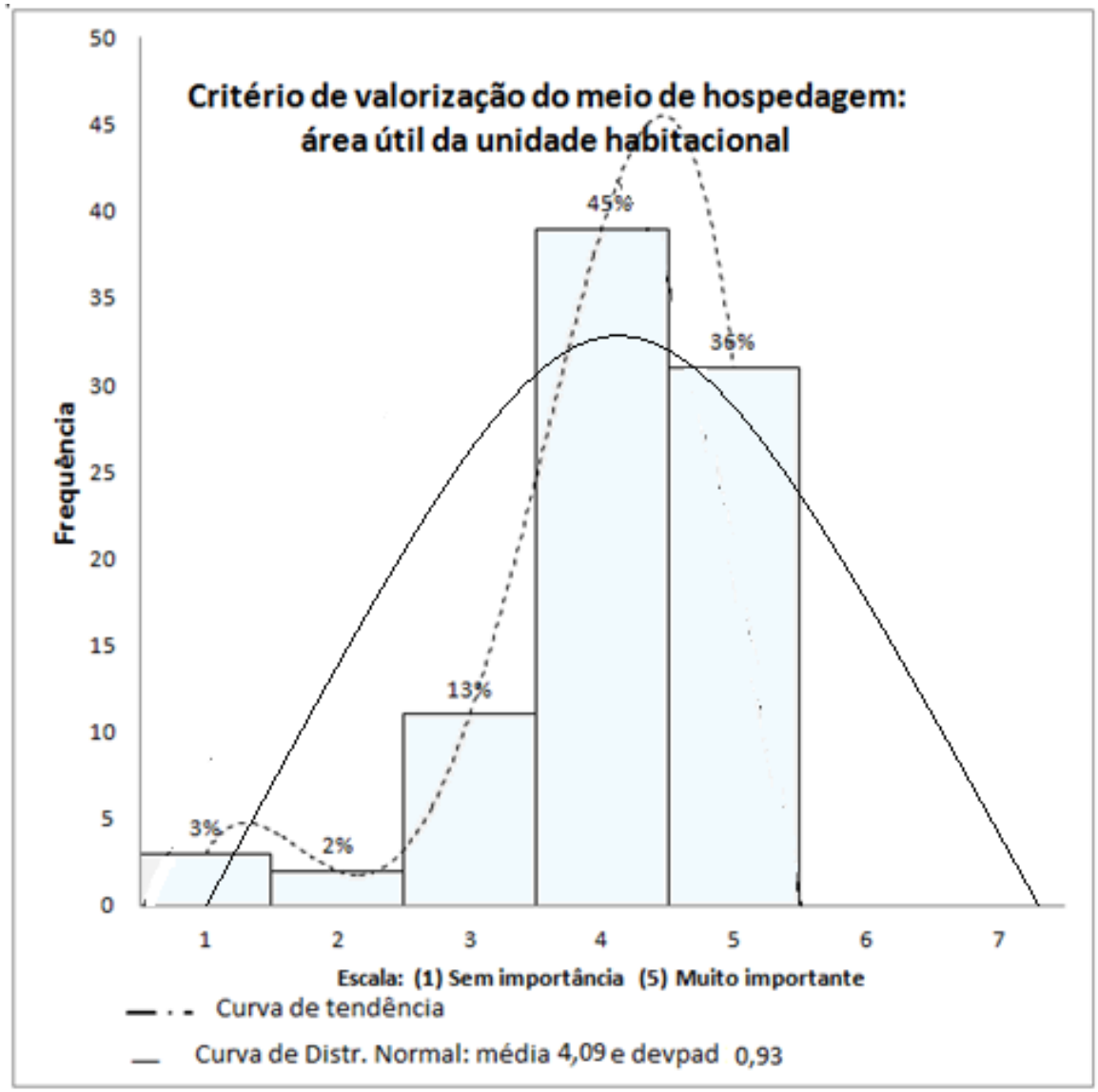

Fonte: Elaborado pelos autores (2016)

Com relação à presença de área útil na unidade habitacional (gráfico 5), a classificação média na escala de 1 a 5, nos mostra que em média os hóspedes avaliam como 4,09, ou seja, o conjunto se estabiliza mais próximo a da opinião "importante". A curva de distribuição Normal dos dados em torno da média 4,09, considerando o desvio padrão de 0,93, mostra que aproximadamente $70 \%$ dos dados estão próximos à média, com valores entre 3,16 e 5,02. Ao observar a sobreposição do histograma de frequências relativas com a curva Normal, observamos que os dados se aproximam da média pelo lado direito da média, indicando uma forte tendência das opiniões se concentrarem em "importante" e "muito importante", quanto à valorização do meio de hospedagem pela presença de área útil na unidade habitacional.

Da mesma forma que o serviço de cofre, a área útil na unidade habitacional é obrigatória no SBClass e também valorizada pelo hóspede. Cabe ressaltar que além de disponibilizar área útil na unidade habitacional, a mesma deve ter $17,00 \mathrm{~m}^{2}$, excluindo desse cálculo o banheiro, ou seja, nota-se uma exigência muito específica do que deve ser oferecido em um hotel cinco estrelas.

Para o aprofundamento dos resultados e discussões, o próximo item é dedicado à análise de possíveis associações entre os diferentes critérios de valorização dos meios de hospedagem.

\subsubsection{Análises de associações entre diferentes critérios de valorização dos meios de hospedagem}

Dizemos que duas variáveis estão associadas, se o conhecimento de uma altera a probabilidade de algum resultado da outra (MORETTIM; BUSSAB, 2013). Os critérios de valorização dos meios de hospedagens, bem como outras variáveis estudadas nesse trabalho indicam 
atributos que permitem que sejam tratadas como dados categorizados. Por exemplo, observamos o gráfico 6, que traz as frequências das variáveis "sexo" e "levam em conta o número de estrelas do meio de hospedagem ao definir sua escolha".

Gráfico 6 - Distribuições de frequências das variáveis sexo e hóspedes que levaram em conta o número de estrelas da classificação do meio de hospedagem

\section{Distribuição da ocupação segundo o sexo}

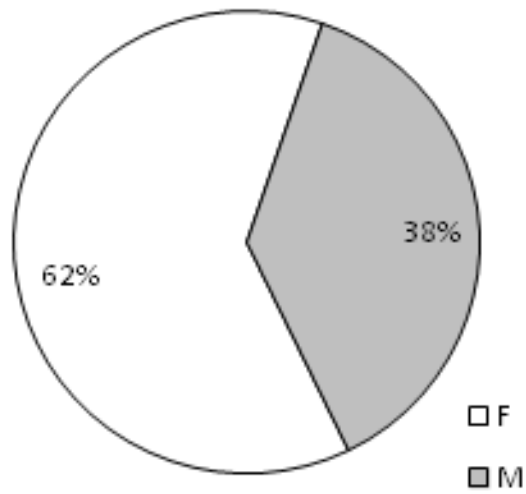

Hóspedes que levaram em conta o núm ero de estrelas do meio de hospedagem ao definir sua escolha.

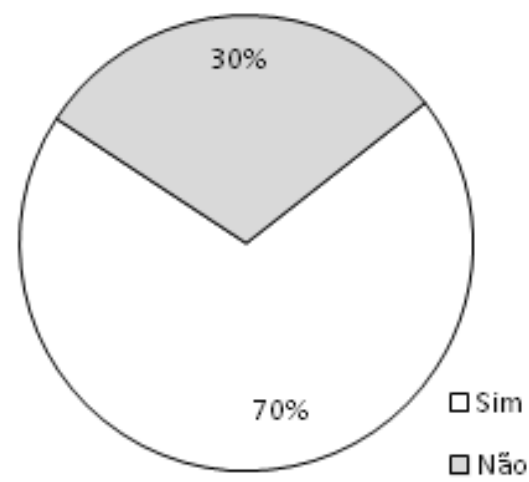

Fonte: Elaborado pelos autores (2016)

Analisando ambas as distribuições, podemos concluir que a maioria da ocupação é constituída pelo sexo feminino e também que a maioria leva em conta o número de estrelas do meio de hospedagem. Mas, será que podemos afirmar que o fato do hóspede ser do sexo feminino faz com que ele leve em conta o número de estrelas do meio de hospedagem? Para responder a esta questão, avaliamos o grau de associação entre ambas as variáveis.

Sob um aspecto qualitativo, analisamos as associações utilizando o teste de associação o qui-quadrado $\left(\mathrm{X}^{2}\right)$. Para esta análise, as variáveis de interesse na investigação foram dispostas em tabelas de contingência para que duas hipóteses fossem testadas. Trabalhamos com duas hipóteses a testar:

- Hipótese nula $\left(H_{0}\right)$ : não há associação entre as variáveis;

- Hipótese alternativa, $\left(H_{a}\right)$ : há associação entre as variáveis;

Como primeiro teste, aplicamos o qui-quadrado para avaliar se existe ou não associação entre as variáveis "sexo" e "se levou em conta o número de estrelas para escolher o meio de hospedagem" e entre as variáveis "sexo" e "disponibilização de colchões em padrão grande". Para isto, organizamos ambas variáveis nas tabelas de contingência (Tabelas 2 e 3 ). 
Tabela 2 - Contingência para análise de associação entre sexo e se levou em conta o número de estrelas do hotel ao definir sua escolha

\begin{tabular}{|c|c|c|c|c|}
\hline Sexo & $\mathrm{O} / \mathrm{E}$ & Sim & não & total \\
\hline \multirow{2}{*}{$\mathrm{F}$} & $\mathrm{O}_{\mathrm{F}}$ & 37 & 16 & 53 \\
\hline & $\mathrm{E}_{\mathrm{F}}$ & 36,98 & 16,02 & 53 \\
\hline \multirow{3}{*}{$M$} & $\mathrm{O}_{\mathrm{M}}$ & 23 & 10 & 33 \\
\hline & $\mathrm{E}_{\mathrm{F}}$ & 23,02 & 9,98 & 33 \\
\hline & Total & 60 & 26 & 86 \\
\hline
\end{tabular}

Fonte: Elaborado pelos autores (2016)

Nesta análise, trabalhamos com duas hipóteses:

- Hipótese nula $\left(H_{0}\right)$ : não há associação entre o sexo do hóspede e a valorização através do número de estrelas do meio de hospedagem;

- Hipótese alternativa, $\left(H_{a}\right)$ : há associação entre o sexo do hóspede e a valorização através do número de estrelas do meio de hospedagem, portanto, estas duas variáveis consideradas dependentes entre si.

Calculamos os valores de frequência esperados para ambos os sexos e opiniões em relação ao número de estrelas do meio de hospedagem, e o coeficiente qui-quadrado para a tabela 2 , obtemos $x^{2}=0,00004326664$, que analisado a um nível de significância de $5 \%$, nos permite avaliar que a hipótese que prevalece, neste caso, é $\mathrm{H}_{0}$. Concluímos então que as variáveis sexo e importância do número de estrelas na hora de escolher o meio de hospedagem não estão associadas.

Com relação à análise referente à valorização do meio de hospedagem pela disponibilidade de colchões em padrão grande e o sexo do hóspede, resumimos as informações na tabela 3.

Tabela 3 - Contingência de valores de frequências

Critérios de valorização: disponibilidade de colchões em padrão grande

\begin{tabular}{|c|c|c|c|c|c|c|c|}
\hline & O/E & Sem & Pouco & indiferente & importante & muito & total \\
\hline sexo & & importância & importante & maneremte & importante & importante & total \\
\hline \multirow{2}{*}{$\mathbf{F}$} & $O_{F}$ & 1 & 1 & 3 & 16 & 32 & 53 \\
\hline & $\mathbf{E}_{F}$ & 0,6162 & 0,6162 & 3,6977 & 18,4884 & 29,5814 & 53 \\
\hline \multirow{2}{*}{$\mathbf{M}$} & $\mathbf{O}_{M}$ & 0 & 0 & 3 & 14 & 16 & 33 \\
\hline & $\mathbf{E}_{F}$ & 0,3837 & 0,3837 & 2,3023 & 11,5116 & 18,4186 & 33 \\
\hline Total & 0 & 1 & 1 & 6 & 30 & 48 & 86 \\
\hline
\end{tabular}

Fonte: Elaborado pelos autores (2016)

Portanto, trabalhamos com duas hipóteses:

- Hipótese nula $\left(H_{0}\right)$ : não há associação entre o sexo do hóspede e a valorização através do padrão de colchão oferecido;

- Hipótese alternativa, $\left(H_{a}\right)$ : há associação entre o sexo do hóspede e a valorização através do padrão de colchão oferecido sendo, portanto, estas duas variáveis consideradas dependentes entre si.

Calculamos os valores de frequência esperados para ambos os sexos e opiniões em relação à valorização do padrão de colchão oferecido, e o coeficiente qui-quadrado para a tabela 3 , obtemos $X^{2}=3,03$, que analisado a um nível de significância de $5 \%$, usando uma tabela da distribuição qui-quadrado, nos permite avaliar que a hipótese que prevalece, neste caso, é $\mathrm{H}_{0}$. Concluímos então que as variáveis sexo e disponibilidade de colchões em padrão grande, no que 
diz respeito à valorização do hotel não estão associadas.

Em ambas as análises, as diferenças, verificadas na amostra entre a proporção de homens e de mulheres que levam em conta o número de estrelas da classificação do meio de hospedagem e a disponibilização de colchões em padrões grandes, podem ser explicadas meramente por variações casuais da amostragem.

Isso mostra que não necessariamente alguns resultados são conclusivos para o alcance dos objetivos propostos, mas permitem melhor conhecimento do que se está estudando. Por isso, além da associação entre variáveis (critérios de valorização), também se realizou a análise quantitativa dos dados, a qual é descrita no próximo item.

\subsubsection{Análise quantitativa dos dados}

Analisando as variáveis sob um ponto de vista quantitativo, avaliamos o grau de correlação entre alguns pares de critérios de valorização dos meios de hospedagens. Para se medir o grau de correlação entre duas variáveis utilizamos o coeficiente de correlação de Pearson $(r)$. Sendo que $r$ varia de -1 (correlação total negativa) a +1 (correlação total positiva) (BARBETTA, 2010). Neste caso, $r=0$ indica ausência total de correlação.

A tabela 4 resume a investigação quanto a opinião do hóspede que valoriza a disponibilização de serviço de recepção durante 24 horas, com a valorização da disponibilização do serviço de mensagens por 24 horas. Encontramos um coeficiente de correlação $r=0,41$, demonstrando uma fraca correlação entre estes dois critérios de valorização. Assim, podemos concluir que a importância que o hóspede dá ao fato do meio de hospedagem disponibilizar o serviço de recepção durante 24 horas não está baseada na possibilidade desta recepção oferecer serviços de mensagens e sim, a outros fatores.

Tabela 4 - Correlação entre os critérios de valorização Serviço de recepção aberto 24h versus Serviço de mensagens $24 \mathrm{~h}$

\begin{tabular}{lcc}
\hline \multicolumn{1}{c}{ Descrição } & $\begin{array}{c}\text { Serviço de recepção } \\
\text { aberto } 24 \mathrm{~h}\end{array}$ & $\begin{array}{c}\text { Serviço de } \\
\text { mensagens 24h }\end{array}$ \\
\hline Média & 4 & 3 \\
Desvio padrão & 0,80 & 1,25 \\
amostra & \multicolumn{2}{c}{85 elementos } \\
\multicolumn{2}{c}{$r=$} & $\mathbf{0 , 4 1}$ \\
\hline \multicolumn{2}{c}{ Fonte: Elaborado pelos autores (2016) }
\end{tabular}

Fonte: Elaborado pelos autores (2016)

Da mesma forma, mostra-se indiferente a disponibilização do serviço de concierge (Tabela 5), que possui correlação muito fraca $(r=0,28)$ com a disponibilização do serviço de recepção 24 horas nos meios de hospedagens.

Tabela 5 - Correlação entre os critérios de valorização

\begin{tabular}{lcc}
\hline \multicolumn{1}{c}{ Descrição } & $\begin{array}{c}\text { Serviço de recepção } \\
\text { aberto } 24 \mathrm{~h}\end{array}$ & $\begin{array}{c}\text { Serviço } \\
\text { concierge }\end{array}$ \\
\hline Média & 4 & 3 \\
Desvio padrão & 0,80 & 1,02 \\
amostra & \multicolumn{2}{c}{86 elementos } \\
\multicolumn{2}{c}{$r=$} & $\mathbf{0 , 2 8}$ \\
\hline \multicolumn{2}{c}{ Fonte: Elaborado pelos autores (2016) }
\end{tabular}


Com relação aos critérios que remetem à execução de atividades on-line nos quartos, a tabela 6 mostra que os hóspedes consideram, em média, muito importante (5 na escala) que os quartos do meio de hospedagem possuam acesso à internet. No entanto, consideram em média indiferente ( 3 na escala) o quarto possuir mesa para trabalho. O coeficiente $r=0,21$ mostra uma fraca correlação entre os dois critérios.

Tabela 6 - Correlação entre os critérios de valorização Acesso à internet no quarto versus Mesa de trabalho no quarto

\begin{tabular}{lcc}
\hline \multicolumn{1}{c}{ Descrição } & $\begin{array}{c}\text { Acesso à internet no } \\
\text { quarto }\end{array}$ & $\begin{array}{c}\text { Mesa de trabalho no } \\
\text { quarto }\end{array}$ \\
\hline Média & 5 & 3 \\
Desvio padrão & 0,70 & 1,04 \\
amostra & \multicolumn{2}{c}{86 elementos } \\
\multicolumn{2}{c}{$\quad \mathbf{0 , 2 1}$} \\
\hline
\end{tabular}

Fonte: Elaborado pelos autores (2016)

Já a tabela 7 relaciona as opiniões quanto ao acesso à internet e à disponibilização de serviço de escritório virtual. A opinião média é que é indiferente o serviço de escritório virtual ser oferecido pelos meios de hospedagens ( 3 na escala) e a correlação entre a avaliação deste serviço e a disponibilização de internet nos quartos também se mostrou fraca $(r=0,22)$. Estas análises nos permitem especular que os hóspedes que utilizam a internet no interior dos meios de hospedagens o fazem para outras atividades que não aquelas ligadas ao trabalho - como lazer, acesso a redes sociais, acesso a jogos ou vídeos, por exemplo.

\begin{tabular}{lcc}
$\begin{array}{l}\text { Tabela } 7 \text { - Correlação entre Acesso à internet versus Serviço de escritório virtual } \\
\text { Descrição }\end{array}$ & $\begin{array}{c}\text { Acesso à internet no } \\
\text { quarto }\end{array}$ & $\begin{array}{c}\text { Serviço de } \\
\text { escritório virtual }\end{array}$ \\
\hline Média & 5 & 3 \\
Desvio padrão & 0,70 & 1,03 \\
amostra & \multicolumn{2}{c}{86 elementos } \\
& \multicolumn{2}{c}{$\mathbf{0 , 2 2}$} \\
\hline & Fonte: Elaborado pelos autores (2016)
\end{tabular}

A tabela 8 apresenta a correlação entre a importância dada ao tamanho do banheiro em relação ao conforto do mesmo no meio de hospedagem. Considerando a escala de 1 (sem importância) a 5 (muito importante), podemos perceber que, em média, os hóspedes consideram importante tanto o tamanho, quanto o conforto do banheiro. O coeficiente de correlação entre estes dois critérios de valorização nos mostra que há, por parte dos hóspedes, uma associação de moderada a forte do tamanho com o conforto do banheiro do hotel. Portanto, os hóspedes tendem a avaliar como confortável o banheiro do hotel em relação ao seu tamanho e consideram estes critérios como importantes quanto à avaliação do meio de hospedagem como um todo.

Tabela 8 - Correlação entre Tamanho do banheiro versus Conforto do banheiro

\begin{tabular}{lcc}
\hline Descrição & Tamanho do banheiro & Conforto do banheiro \\
\hline Média & 4 & 4 \\
Desvio padrão & 0,83 & 0,80 \\
amostra & \multicolumn{3}{c}{80 elementos } \\
$\quad r=$ & $\mathbf{0 , 7 0}$ \\
\hline
\end{tabular}

Fonte: Elaborado pelos autores (2016) 
Esses resultados demonstram que a importância dada ao serviço de recepção 24 horas não está relacionada ao serviço de mensagem, nem ao serviço de concierge, como mostrou a Tabela 5, destacando que a necessidade do hóspede pela recepção está pautada por outros motivos. Sobre a questão da internet disponível no quarto, também não encontramos relação com a disponibilização de mesa de trabalho na unidade habitacional ou escritório virtual, o que pode conduzir uma possível tomada de decisão de infraestrutura para o meio de hospedagem, precisando investir em acesso à internet dentro das unidades habitacionais, e não na infraestrutura de móveis ou espaços de escritório virtual, otimizando investimentos.

Por fim, algo que também pode ser usado como base para decisões centra-se no banheiro, indicando aos gestores que este é um espaço considerado pelos hóspedes, que possa ser considerado em termos de investimentos financeiros.

\section{CONCLUSÃO}

A partir do que foi analisado, tanto qualitativa quanto quantitativamente, pode-se apontar que para a legitimidade do Sistema Brasileiro de Classificação dos Meios de Hospedagem (SBClass), é preciso considerar além de critérios mandatários (obrigatórios) ou eletivos (opcionais) para cada categoria e tipo de meio de hospedagem em si (hotel, hotel fazenda, pousada, resort, flat/aparthotel), as necessidades, os itens de satisfação e o perfil do público-alvo. As análises sugerem que se pode usar como base a razão da viagem ou hospedagem do cliente (passeio, negócios, trabalho, visita à familiares) para a construção de um perfil dos clientes do meio de hospedagem, identificando essa informação no próprio check-in.

Além disso, com o público-alvo do meio de hospedagem e seu perfil claramente definidos, é possível verificar os critérios ditos essenciais ou mais importantes para esse público, permitindo maior assertividade de gestores e empresários na tomada de decisão para investimentos e melhorias, descartando investimentos desnecessários, ou que apenas resultem em uma categoria que não reflita o que o cliente precisa saber sobre os serviços e acomodações do meio de hospedagem. Ratificando essa questão inúmeros estudos demonstram a relação existente entre o motivo da viagem ou hospedagem, bem como o perfil do hóspede e o que espera do meio de hospedagem.

Nesse sentido, Figueiredo et al. (2011), afirmam que um público de idade avançada, é muito sensível às condições estabelecidas pelos meios de hospedagem. Contudo, os "hóspedes seniores não apreciam ser tratados como um grupo distinto", precisam sim ser "[...] acolhidos e tratados com familiaridade; poderem recolher-se em locais calmos e afastados da agitação; sentirem-se seguros no hotel e nos espaços públicos envolventes; disporem de apoio de saúde em caso de necessidade [...]" (FIGUEIREDO et al., 2011, p. 565), ou seja, uma extensão de sua casa.

Outro estudo é o de Ortega et al. (2013), que tem como foco os indivíduos participantes de eventos de peregrinação, os quais se encontram em um estado espiritual intenso, incentivados por suas crenças e trazendo, até mesmo, um sentimento de penitência. Aqui é encontrada uma exceção em relação às características de qualidade e satisfação, este perfil de hóspede leva em consideração a maneira de expressar suas crenças e não dão atenção a fatores de conforto encontrados nos meios de hospedagem.

A respeito da pesquisa desenvolvida, além das pesquisas adicionais mencionadas, pode-se dizer que para o perfil de consumidor de serviços de hospedagem evidenciado; maduro (acima dos 40 anos), feminino, por motivação principal de passeio, proveniente principalmente do Rio Grande do Sul e do interior de Santa Catarina, e que prefere os meios de hospedagem classificados como 
"hotéis"; os itens essenciais são àqueles relacionados ao conforto do hóspede, tais como: disponibilização de colchões com tamanho grande, minirefrigerador no quarto, TV por assinatura, estacionamento próprio, a percepção de treinamento dos funcionários e facilidades de pagamento como cartões de débito e crédito, bem como a prática de reciclagem de materiais. Apesar desses respondentes afirmarem que têm como base de escolha o número de estrelas do meio de hospedagem.

Outros aspectos foram mencionados como de significativa relevância, são eles: serviço de cofre, recepção aberta 24 horas, a presença de área útil e acesso à internet na unidade habitacionais, e ainda o tamanho e o conforto do banheiro. Outros pontos foram considerados indiferentes, sugerindo que amplos investimentos do meio de hospedagem garantiriam o número de estrelas, mas não impactariam em satisfação.

Portanto, o que a análise da amostra permitiu concluir - com as devidas limitações - é que para o sistema de classificação ser legítimo precisa ter como base a perspectiva do cliente, garantindo fidedignidade no processo de classificação, permitindo o uso do Sistema para seu verdadeiro fim, ou seja, como "um importante mecanismo de comunicação com o mercado e o modo mais adequado para o consumidor escolher quais meios de hospedagem deseja utilizar" (MINISTÉRIO DO TURISMO, 2010, p. 3). Finalmente, sugere-se a continuidade do estudo, ampliando a amostragem, que contemple a representatividade de públicos diversos para a formulação de diferentes perfis de clientes e, possivelmente, a estruturação de novas categorias de classificação ou tipos de meios de hospedagem, em que o público-alvo é o aspecto basilar.

\section{REFERÊNCIAS}

ANDRADE, Maria Margarida de. Introdução à Metodologia do Trabalho Científico. 7. ed. São Paulo: Atlas, 2006.

ANGELI, Ana Carolina Barbosa. Resenha do livro Hospitalidade: a inovação na gestão nas organizações prestadoras de serviços. Revista Hospitalidade, São Paulo, v. 7, n. 2, p. 143-145, jul./dez. 2010.

BARBETTA, Pedro Alberto. Estatística aplicada às Ciências Sociais. 7. ed. Florianópolis: Ed. UFSC, 2010.

BRASIL. Lei n. 11.771, de 17 de setembro de 2008. Dispõe sobre a Política Nacional de Turismo, define as atribuições do Governo Federal no planejamento, desenvolvimento e estímulo ao setor turístico. [2008]. Disponível em: <http://www.planalto.g ov.br/ccivil_03/_ato2007-2010/2008/lei//11771.htm> Acesso em 16 abr. 2015.

CANDIOTO, Marcela Ferraz. Agências de turismo no Brasil: embarque imediato pelo portão dos desafios. Rio de Janeiro: Elsevier, 2012.

FERNÁNDEZ, M. Concepción López; BEDIA, Ana M. Serrano. Is the hotel classification system a good indicator of hotel quality?: An application in Spain. Tourism Management, v. 25, p. 771-775, dez. 2004.

FIGUEIREDO, Wilson Zacarias et al. Hotéis Atrativos a Hóspedes Seniores: A Experiência da Região do Algarve. In: International Conference on Tourismo \& Management Studies, 2011, Algarve. Book of Proceedings... Algarve: Universidade do Algarve, 2011. p. 565-578.

GIL, Antônio Carlos. Como elaborar projetos de pesquisa. 4. ed. São Paulo: Atlas, 2002.

JOÃO, Iraci de Souza; MERLO, Edgard Monforte; MORGADO, Ricardo Rodrigues. Análise dos atributos valorizados pelo consumidor de hotelaria do segmento econômico: um estudo exploratório. Revista Turismo - Visão e Ação, v. 12, n. 01, p. 04-22, jan./abr. 2010. 
KARASSAWA, Neuton S. A qualidade da logística no Turismo: um estudo introdutório. São Paulo: Aleph, 2003.

KUSHANO, Elizabete Sayuri; ALMEIDA, Wolney Gomes. Inclusão Social, Cidadania e Turismo: uma investigação sobre a existência de serviços adaptados às pessoas com necessidades especiais nos meios de hospedagem da região metropolitana de Curitiba. Revista Brasileira de Pesquisa em Turismo, v. 02, n. 04, p. 88-101, dez. 2008.

LADEIRA, Wagner Júnior; SANTINI, Fernando; COSTA, Gustavo. Antecedentes e dimensões da experiência de consumo: uma abordagem experimental na satisfação de hóspedes. Turismo em Análise, v. 24, n. 01, p. 119-144, abr. 2013.

$\mathrm{LI}$, Gang et al. Identifying emerging hotel preferences using Emerging Pattern Mining technique. Tourism Management, v. 46, p. 311-321, Feb. 2015.

LIMBERGER, Pablo Flores; BOARIA, Francieli; ANJOS, Sara Joana Gadotti dos. A relação entre a satisfação geral e as variáveis da satisfação na hotelaria em hotéis de excelência. Revista Brasileira de Pesquisa em Turismo, São Paulo, v. 08, n. 03, p. 435-455, set./dez. 2014.

MARTINELI, José Celso. Fundamentos multidisciplinares do turismo: hotelaria. In: ANSARAH, Marília Gomes dos Reis (Org.). Turismo: Como aprender, como ensinar. São Paulo: Editora SENAC, 2001. p. 147166.

MENEZES, Paula Dutra Leão de; SILVA, Jéssica Cristina. Análise do Sistema Oficial de Classificação dos Meios de Hospedagem do Brasil. Revista Iberoamericana de Turismo, v. 03, n. 01, p. 57-70, 2013.

MINISTÉRIO DO TURISMO. Cartilha de Orientação Básica: Sistema Brasileira de Classificação de Meios de Hospedagem. Brasília: Coordenação e Execução Ministério de Turismo e Fundação Universa, 2010.

MONTEJANO, Jordi Montaner. Estrutura do Mercado Turístico. 2. ed. São Paulo: Roca, 2001.

MORETTIN, Pedro Alberto; BUSSAB, Wilton de Oliveira. Estatística básica. 8. ed. São Paulo: Saraiva, 2013.

ORTEGA, Isadora Mencarelli et al. Turismo religioso em Aparecida do Norte, SP: infraestrutura de hospedagem do ponto de vista do visitante. Revista de Investigación em turismo y desarrollo local, v. 06, n. 14, p. 1-22, jun. 2013.

PARASURAMAN, A.; ZEITHAML, Valarie A.; BERRY, Leonard L. A conceptual model of service quality and its implications for future research. Journal of Marketing, v. 49, p. 41-50, 1985.

SANTOS, Glauber Eduardo de Oliveira. O que determina a satisfação dos turistas internacionais no Brasil? Turismo em Análise, v. 24, n. 03, p. 521-543, dez. 2013.

SBTUR. Quem somos. Disponível em: < https://www.sbtur.com/site/quem-somos>. Acesso em: 30 set. 2015.

THOMAS, Jerry R.; NELSON, Jack K.; SILVERMAN, Stephen J. Métodos de pesquisa em atividade física. 6. ed. Porto Alegre: Artmed, 2012.

TUCH, David Lord; SPOLON, Ana Paula Garcia. Planejamento hoteleiro. In: ANSARAH, Marília Gomes dos Reis (Org.). Turismo: Como aprender, como ensinar. São Paulo: Editora SENAC, 2001. p. 353-374.

VAZ, Gil Nuno. Marketing Turístico: receptivo e emissivo um roteiro estratégico para projetos mercadológicos públicos e privados. São Paulo: Pioneira, 2002. 